\title{
Interview
}

\section{Interview with Abby DeMillo, Senior Director of Content Management Technology}

\section{Michael Moon}

is President of GISTICS and a lecturer and leading authority on digital asset management, automation of marketing services and multichannel brands. He has delivered more than 300 keynotes, presentations, executive seminars, workshops and web-based seminars around the world. His book Firebrands: Building Brand Loyalty in the Internet Age has been published in 13 different languages. He also conducts primary research through surveys and one-to-one interviews. Michael and his team advise international-brand corporations on multichannel strategies for brand management and digital asset management, including Amway, Boeing, Disney, Frank Russell Company, Gap, General Motors, FCB, Hallmark, Hasbro, Leo Burnett, Nokia, Sanoma WSOY, TeliaSonera, Thomson Corporation, VF Corp and Warner Bros.

\section{Keywords: XML, publishing, X query, DRM, workflow, McGraw-Hill}

Abstract XML publishing is a way to transform your content into meaningful tags, meaningful schema that can be read by any receiving system. So by translating your content into $X M L$, you're making your content truly neutral. And the tags that surround it - the schema that surrounds it - is schema that can be interpreted by a number of different systems. So the key is to be able to create your content once and publish it many times - and this has only recently become achievable through XML publishing.

Journal of Digital Asset Management (2007) 3, 221-229. doi:10.1057/palgrave.dam.3650098

Michael Moon: Why don't we just start off with your current situation at McGraw Hill. Title and responsibilities and things like that.

Abby DeMillo: I am Senior Director of Content Management Technology for the Business Information Group's IT Division of McGraw-Hill. The Business Information Group, or BIG, is a part of the Information and Media Segment of McGraw-Hill.

Michael Moon: What are some of the McGraw Hill properties or brands that fall under that, or that you guys support?

Abby DeMillo: The three supported businesses are McGraw Hill Construction, The Aviation Week Group, and Platts.

Michael Moon: And Platts is a directory of some sort?

Abby DeMillo: No, Platts is a provider of energy and metals information. Platts is a global business with customers spanning across more than 150 countries. We have 14 offices worldwide, and serve markets such as oil, natural gas, electricity, nuclear power, coal, petrochemical and metals.
We offer Platts' customers real-time news, pricing, and analytic data which helps them to operate within their respective markets with transparency and efficiency. Traders, risk managers, analysts and industry leaders depend upon Platts to help them make better trading and investment decisions.

Platts is a very interesting part of the business. We do data analytics. We send that data out to professionals - trading brokers and other financial professionals - on a real-time basis. We aggregate it with our written content.

Michael Moon: Like pricing and availability?

Abby DeMillo:Yes.

Michael Moon: That's a perfect context. We're doing a special session in the Journal of DAM on Digital Supply Chains for Content or Digital Supply Chains for Multimedia Content, and publishing media in entertainment.

As you're familiar with the Journal of DAM in terms of the kinds of people that write in it, and the overall focus... It tends to be higherlevel, with more thought leaders in the DAM community. Much like yourself. 
We'd like to here start with a brief overview of DAM at McGraw Hill. DAM and/or related content-management or automated publishing at McGraw Hill as a way of setting the context for the next wave of DAM - which we're characterizing as digital supply chains.

Abby DeMillo: I have to be very careful here and not betray our strategy or our specifics. We see DAM as just a piece of the whole puzzle, or a piece of the whole supply chain. Actually, that's reflected in how my job role has changed over the course of the last 8 or 9 years.

I've been in the content space for a while, now. As the content-management industry matures, my job role has become more mature. So I no longer am just the person controlling DAM and content-systems integrated into that. We're really truly looking at the entire supply chain of digital assets. Digital information from beginning to end. That includes structured and unstructured content, as well.

Michael Moon: Could you spend a moment and just give a quick survey or overview of what the key areas or aspects are of a digital supply chain in terms of either systems technologies and/or types of content?

Abby DeMillo: Well, I will talk about it in very general terms, because I think this can apply to any industry or any company. Not just the company that I'm serving right now.

In general, your supply chain really is content-inclusive of all content types that help build products and services for a customer base - either internal or external. I look at it as outside of the security layer. I look at transactional content, or content that is within a security layer, such as e-commerce content and customer profile information. Transactional content has to be treated differently because of all of the aspects of permissioning and rights management that protect customers.

Everything outside of that, which is inclusive of structured and unstructured content, is really part of your supply chain and your flow of content. DRM relating to photographs and illustrations, for instance, is a different type of security than financial systems and back-office systems. It's a type of rights management that needs to be in the hands of the business owners. It's relating to what you're using those images for.

Photographs and illustrations, because they're objects and because there are photographers and illustrators that deserve to be recognized, keywords and contract or credit information are important to that content supply chain. Those objects are treated differently than transactional information or secure customer information. Objects reside in object repositories while structured information lives within a relational database.

When I'm talking about content, I'm talking about free text content, illustrations, photographs and all the imagery. I haven't really been involved in broadcast in my career, but it would include broadcast imagery, as well.

It also includes product information - touts - things that you're saying about the content that you're trying to sell. So if you're writing about the book, your content includes the book and all of the elements within the book. But also, what you're selling the book for and blurbs and information that appear on your website, for instance, to help sell that book.

It goes through an editorial flow, but it also goes through - depending on the business model - an e-commerce flow or a web flow that will serve that content back up to the customers at a subscription rate, or a pay-perview rate for instance.

A content "supply chain" follows a lifecycle from ingestion or contribution to management to storage to output. Much like you would manage a project, the lifecycle really has a beginning, a middle, and an end to it. That's the whole trail that we follow. I could be actually working for another industry, but I would still follow the same lifecycle for those assets and that content that is important to that industry. And the ultimate benefit of a well managed content life cycle is content reuse.

I think what has really opened up the whole arena of content lifecycle and of the ability for companies to create new products and services based on content without having to reinvent the wheel every time has been XML publishing. XML publishing has allow businesses to really truly create media-neutral content.

Michael Moon: Could you maybe spend a paragraph or two explaining XML publishing? Abby DeMillo: XML is a mark up language and XML publishing is a way to transform your content into meaningful tags, meaningful schema that can be read by any receiving system. That's 
not a real scientific explanation of it, but XML basically neutralizes your content. Using XML schema - whether you're using PRISM standards or whatever standards you're using. If it is understood by the receiving party, it's able to be translated into a number of different platforms.

So by translating your content into XML, you're making your content truly neutral. And the tags that surround it - the schema that surrounds it - is schema that can be interpreted by a number of different systems.

For instance, if you're in Adobe to create your print content, you may use $\mathrm{K} 4$ as the tool to translate the templates that you have used for your print content into XML tags. By doing that, you're able to syndicate your content.

So the key is to be able to create your content once and publish it many times. That's been the holy grail for over 10 years now that I've been in this business, but it has only recently been achievable through XML publishing.

Michael Moon: Are you using any kind of special XML databases or XML content databases for storing and reconstituting this neutral or fluid content?

Abby DeMillo: Fluid content. That's a good way to put it. And there are plenty of companies that are popping up in the industry with capabilities to manage and store XML content. There are tools that are out there in the industry now that actually take XML schema and break it up into nodes, at the node level, and are able to manage that. There are a number of companies that are popping up all over the place that really are focused only on XML management and repositories.

There is a book called, "The Tipping Point" by Malcolm Gladwell. The phrase 'tipping point' refers to the moment when a previously rare phenomenon rapidly becomes a part of common life. Like when a small amount of weight is added to a balanced object, it can cause it to suddenly and completely topple. XML publishing is the tipping point for consumer-driven content. XML opens the door to allow businesses to manage XML schemas in such a way that content can be served up according to the needs of the users.

It's a great thing for publishers and a great thing for media companies, because that is the key. Not to be able to store your schema in one huge document, but to be able to break it up and reassemble it, so that you can provide a new service or a new product.

Just putting your content in XML isn't enough. You have to be able to break it up, manage it, and store it. XML databases are really something that companies need to be looking at, if they're expecting their business models to change in that fashion.

Michael Moon: One of the things that [Carl Hixon] at the LA DAM Symposium showed. He showed an example of doing what he called an "X Query," as a way of assembling new textbooks almost on-demand. Or new compilations or aspects of textbooks to create custom study books or syllabus and that sort of thing. Is that what you're talking about?

Abby DeMillo: Yes. That's exactly what I'm talking about. "X Query," is one of the functions of an XML database that allows you to search XML data. To be able to pull them up and deliver content in this way offers the same advantage as a search engine. X-Query is a way to query the XML database for the tags that you need.

So, yes, it's a big eye-opener.

Michael Moon: What I saw when [Carl] demonstrated this was the ability to quite literally reflow material that was in one textbook into a different template, while maintaining all of the basic formatting, in terms of types and heads, subheads and footnotes and all that sort of stuff.

Abby DeMillo: Yes. It can be an impressive demonstration if you have never seen content handled that way before.

Michael Moon: We're interviewing him in a couple of weeks on his take on digital supply chains, as well.

Abby DeMillo: Carl's team works for the McGraw-Hill Education Segment. Even though we are in different segments of the company, we do have the opportunity to exchange ideas/ information. There's a corporate overseeing governance body that ensures that all of the segments are all talking to each other and exchanging information.

Michael Moon: This gets to another element of the digital supply chain that I wanted to investigate at another publisher - unnamed at this point. It created an internal stock media 
market. Almost like an internal Corbis or Getty Images. Just for all of its media assets.

It facilitated a funny-money transaction thing among various divisions, so that various divisions that created media assets could sell them to sister divisions. Oftentimes at $1 / 10$ th of the cost.

It wasn't really real money. It was just all internal.

Abby DeMillo: Chargebacks or whatever. Right?

Michael Moon: Exactly. Do you see that as relevant, important or is that something you're doing?

Abby DeMillo: No. Not to what we're doing.

But it is relevant to some businesses. It's not something that we're going to get involved in. I don't know about [Carl]. But it is relevant to some businesses.

For instance, a publishing company with many divisions that are using or have the need to reuse imagery - probably 10 s of thousands of dollars or 100s of thousands of dollars are spent every year for the same licenses. Stock houses or agencies may not be able to tell you that they've just licensed that exact same image you want to use in North America to your European office. So a lot of money is spent on duplicate licenses, or licenses that haven't been purchased on a global nature. But that publishing company had one common repository or system for managing images, that company could keep track of the versions and licenses of those images as well as how often those images were used.

Michael Moon: To give you a proof point on that, in an interview I did many years ago with a Microsoft Multimedia Production Group... heading up at that time, or the DAM part of it... was being run by Kevin [Camerford] whom I believe is also going to be publishing an article, here.

He talked about their particular group doing all of the multimedia production for all of the CD-ROMs when that was a big thing. MSN and some of the other online properties.

It turned out that there was this Bengal tiger that had become a brand icon mascot for a whole bunch of different Microsoft-related things. When they consolidated all of their assets into one DAM, they had discovered that they had paid for this Bengal tiger...

Abby DeMillo: Probably like 100 times — right? Michael Moon: 47 times.
Oh, my gosh!

Michael Moon: At $\$ 500$ a clip.

Abby DeMillo: Yes. That's exactly what I'm talking about.

Michael Moon: Just that one photograph. Abby DeMillo: So to have that content "reuse" model where you have this internal Corbis repository where people are checking in and checking out assets - as long as you have cleared permissions. What is it - unlimited usage or whatever they call it now... It's really a brilliant way to take care of chargebacks.

Michael Moon: In much the same way — back to this other publishing firm that I interviewed a while ago... It turned out that they spent an extraordinary amount of time and money creating custom illustrations. Medical illustrations. Anatomical parts. Molecules. That kind of stuff.

There were divisions that wanted to share. "Say - I'd like to use that particular shouldermuscle thing — or throat - muscle and bone of a foot, or something." They were spending about $\$ 1,500$ to 2,000 an illustration, where somebody would actually sit down and draw it. In this case, using some of the digital tools.

The CFO of the organization mandated that every group must submit its finalized artwork to a shared server, where a DAM went and basically had a hot folder. That uploaded it into the DAM.

They furthermore mandated that anyone could use one of these pieces of artwork, but they had to pay out of departmental budgets through a chargeback mechanism, at $1 / 10$ th the fair market price.

As they did this across particular book divisions or publishing division, here's what they discovered. First of all, across a pilot study of 4 publications, having a repository of shareable assets reduced time-to-market for publications by 7 weeks. There were a total of 8 production meetings that no longer needed to occur because the assets were simply available online.

Abby DeMillo: That's because probably a lot of their time was spent researching the same type of assets.

Michael Moon: [Shag-dogging] not even researching. Gophers. [Shag-dogging]. Abby DeMillo: That's a good word.

Michael Moon: Yes.

True. 
Michael Moon: They discovered that they had saved $\$ 20,000$ of direct costs associated with things they didn't have to draw, any more. Plus another $\$ 35,000$ of soft costs, in terms of productivity gains where production assistants and so on were freed up to do other kinds of work.

Abby DeMillo: I think you hit the nail on the head when you started talking about those kinds of benefits. I think that's where companies get quagmired - trying to determine ROI spent on a DAM system. These systems have not gone down in pricing that much over the years.

If you're investing in a truly enterprise repository, you're probably spending a quarter of a million to half a million to three quarters of a million.

Michael Moon:You're spending that just for the license. But then you're also spending another $\$ 3$ or 4 million on professional services and IT support.

Abby DeMillo: Not to mention your hardware environment and digital and disaster recovery. No matter what your setup, you're talking a couple million dollars by the time you're all done with everything.

So companies have a lot of trouble not seeing hard ROI. What you talk about with saving of production time - these are all soft costs. It's very, very difficult when you're trying to justify even a half million-dollar system, to show the company that they would get a good return on their investment within the first 3 years.

Michael Moon: It's hard if you didn't do the activity-based research on the front end documenting exactly who spends how much time shag-dogging after contents and assets.

Abby DeMillo: Yes. That's so important. Conducting a complete (end-to-end) content workflow analysis is so important when you're trying to understand the full content lifecycle of either structured or unstructured content. Where there's a lifecycle, there's a flow of work. If you're going to streamline that lifecycle or if you're going to change it in any way, you have to be able to see the current state and have a good understanding of what the future state needs to look like. Both current and future state need to correlate with how people work, day to day.

Relating this to new product development, if you introduce a new television (or for instance, HDTV) to the market, it's going to change the way people view TV every day, and what channels they use. Like a new product, content management is a technology that can change what choices people make in their daily work life.

If people are used to coming into the office every day and doing their tasks one after another after another, and you're changing their environment, you're going to change their professional life. You're going to change how they work every day.

There's a savings associated with that. Maybe there'll be a process efficiency introduced that you haven't expected, or a better way to organize your staff. But in order to see where the gaps exist - what needs to be improved it's very, very important to map out the current state, and compare that with the future state.

For the technology or the professional services team looking to make some kind of strategic change within a particular business, it is critical to understand how people are working day to day. That includes how much time they're putting in not only tasks, but how much time they're putting in administratively, how they're organized and accountability; who is in charge of what.

As an example, if you're centralizing content flow and you have ten magazines and there's an editor-in-chief in charge of each magazine, do you need ten editors-in-chief? By the time you're done with restructuring that content, workflow, you might find that the business now only needs two or three people at that level because you're centralizing everything. You might find out that organizing your workflow by function rather than product will be a more efficient choice for the business.

So it's really important that workflow be mapped out, and that it is mapped out end to end (from content ingestion or creation through content storage and delivery).

I find often that businesses do part of that, but they don't do the complete flow, end to end. You really have to see how your content enters the lifecycle, how it's being managed, where it "lives" and how it leaves the lifecycle.

Michael Moon: Are you talking about visually depicting that in terms of a large flowchart poster?

Abby DeMillo: Yes. Visually. Get out your Visio diagram and diagram it out. How is your content being handled? What are the decision points? What are the editorial processes? What are you looking to achieve? What is the business problem you're looking to solve by this? 
Implementing content management has to solve a problem.

Michael Moon: Oftentimes, Abby, we've found that when we've participated in mapping the current state, clients and/or users go into that with an idea - almost a hypothesis — as far as the business problems are solved. But in the process of visually depicting an end-to-end business process, they have 1 or 2 or 3 epiphanies. That changes everything!

Abby DeMillo: Oh, of course! That's why doing current flow analysis is so important. Because you don't know, really. You know pretty much the basic problem you want to resolve. But you don't know all of the nuances. You don't know that Mary Jane is sitting there buried within the research department 5 levels below what you're looking at. You're looking at a 50,000-foot view of how your content flows. But you don't know all the people that are involved in that view until you start peeling back the layers. You find that person who's actually putting in 45 hours a week, hunting down that picture or that illustration - and you're wondering, "How are you spending your time? What else could you be doing? To add value to the business if you weren't doing this?".

Michael Moon: In developing these end-to-end process flow maps, you then have to interview almost one-on-one the people that actually do the work.

Abby DeMillo: Oh, yes. Absolutely. For larger organizations, you need to take a "sampling" of people, however, because it is impossible to get to everyone. But make sure that you are interviewing candidates from every type of job role in order to have a realistic view of the workload, workflow and daily problems or issues.

Abby DeMillo: You have to talk to the people - without a doubt. You have to figure out who the stakeholders are.

A very important point is that there has to be somebody within the business who's acting as a champion for this type of effort. Streamlining content-manage lifecycles, and implementing DAM systems is an expensive understanding and not without risks. So having someone on the business side who understands the future state and future business benefits will help your project to succeed.

Michael Moon: Oh, what a joy!

Abby DeMillo: Yes, really! It isn't something like the technology group is going to have this epiphany and go, "Oh, this is what we need to do!" It has to be in response to a business problem. Right?

Whoever is stating that business problem is probably one of your key stakeholders. You just work down from there. You have your key stakeholders and you have all the divisional stakeholders and the workgroup members or resources.

Michael Moon: As we kind of look at the publishing industry... because you've been in the publishing industry for a while - not only with McGraw Hill, but other organizations... One of the things that I've generally observed is that many of the larger publishing firms have had to rethink their internal content flows - if for no other reason than to make their websites a little more economical to produce.

Abby DeMillo: Yes, I Agree.

Michael Moon: Now we're beginning to say, “'Okay.'You've gotten your internal act or your internal house kind of in order. At least it's working better than it was when we had 2 separate unsynchronized disconnected flows in terms of web and print.

Now all of a sudden we're seeing the next wave, which is going outside of the walled garden or outside of our firewall - upstream - in terms of our contributors, authors and subject matter experts - that create or stimulate. They become the catalysts for a bunch of new content creation.

Then all the way downstream in terms of outside - beyond just our corporate boundary. But to partners that are syndicating and repackaging content.

Abby DeMillo: Oh, sure. Well, it's because the businesses are maturing. Right? Just like the evolution of the internet. I actually was at a company once where somebody said, "Well, how could you sell anything on the internet?" That was in 1993. "What a ridiculous thing," they told us, "Who would ever buy anything off the internet?"

Look at where we are, today. Only, 14 years later. Not a long time period has elapsed. It isn't like a whole generation has passed. It's only a decade that's passed, and the whole world has changed because of that. It's just an evolutionary process - and we should always ask ourselves, "what is next?".

Michael Moon: How do you then start to think through or tackle this notion of mapping end-to-end flows through multiple enterprises of a supply chain? 
Abby DeMillo: You don't start with multiple enterprises.

Michael Moon: You start with your own house in order. Right?

Abby DeMillo:You start with your own house in order.You start with whatever the business problem is. You're not going to solve everything all at once, but you have to start somewhere and then keep measuring your success as continue on the journey.

Michael Moon: Let's say the business problem is we've got all of this stuff — we've got all of this content. There's got to be better ways of monetizing it. There's got to be a better way of unlocking the value. Every time we've tried to go out there, people say, "Its really good stuff, but it's not in a usable form." Is that a good statement or problem?

Abby DeMillo: That's a good problem. You're trying to monetize. You have content and you just know there's another way to make money off that content, but you're not sure how to do it.

Michael Moon: Are there any other top-ofmind catalytic events that would be of sufficient magnitude to warrant a policy [inaudible]?

Abby DeMillo: Sure, there are many options available. One way to unlock a hidden value of your content is to increase community involvement on your website. Another option is to go beyond web delivery and into wireless device content channels. There's a business problem for you. Hey. We're publishing a great website. It's very popular. We're making a lot of money, but we want to be able to port this over to the cell phone or the PDA. How do we do that if we're not in XML publishing standards at this point? Or how do we convert our content or syndicate our content out to wireless devices? That's another problem. That's another issue. All of those options open doors of opportunity for your business. They also introduce other issues and risks.

I think what you start with is a case study. You have a use case of, "What is it?" It has to incorporate the vision of the business leader and what he or she wants to do with the business. It has to really always start with the business.

Technology can only enable that to happen. Nowadays with XML standards being more and more defined and XML technologies becoming more sophisticated - we're able to enable all of those visions. But you've got to start with a vision.

So the business has to have an idea or it has to have a problem. Monetizing our current assets so that we can create new services and create new revenue streams. That's a critical business problem for businesses wanting to stay ahead of the competitive curve.

Okay. So what part of your business can you see that happening in? Then take a slice of that. It's all about taking a little slice and creating a pilot program out of that slice, and seeing what you can do in a test market.

I'm a very big believer in proof-of-concepts and pilot testing and validating within a known market that can actually give you feedback and give you something so that you can base your ROI on that. So you can base your projections of revenue.

Many times business stakeholders will ask, "What can technology do for us?" They want to know what possibilities are there through technology in order to envision the future of their business. I think that an opposite approach is needed. You need to envision the possibilities for your business and then see how far you can push the technology envelope. You don't need to know everything that XML publishing can enable in order to figure out that the best way to transform your business is through customer centric marketing and services.

Michael Moon: Increasingly, doing these proofof-concepts or these soft-launch products or services, require or entail the participation of 1 or 2 marketing partners. Is that correct?

Abby DeMillo: Yes. Oh, sure. Probably more than that if it's a complex pilot. Yes.

Michael Moon: Could you speak a little more on how you particularly approach that as a problem or how you work through that?

Abby DeMillo: Well, there are marketing partners and then there are technology partners. So as a technology team, your job is to really take a look at that problem from a technology point of view - from application options, functionality through to the right infrastructure. Identify what planning and preparation steps are needed, and then find the right technology platform that will deliver that type of content in such a way that the business can make use of it.

Then the business - perhaps — will have to partner or collaborate with the marketing arm to be able to help with web-trend analysis or marketing analysis or focus groups or whatever it is that they're going to need in order to judge the value of that program. 
What's interesting about doing a pilot is it marries the business with the technology all the way through to the database level. So you as a team - you're not just getting requirements, doing a project, doing UAT, bouncing it back to the business and then launching, you are really focusing on the specific business case scenario and following it through to validation in the market.

Michael Moon: UAT — User Acceptability?

Abby DeMillo: Yes. User-acceptance testing. Then bouncing back to the business.

In a typical IT project, that's what used to happen. But in a pilot program and in subsequent projects off of that new type of process, you are actually part of the business. So you're partnering with your business. You're working together. You're brainstorming. You're doing think tank work together, to really say, "Okay. This is your business problem, and this is what's out there." We've completed a couple of successful pilot programs at McGraw-Hill and it is very exciting when we see the entire circle completed.

The IT group or team supporting your business, it's their responsibility to help enable the business - the business solution. We can only do that by constantly being out there in the industry and seeing what new vendors are out there that can supply and always remain product-agnostic in your strategy. I'm a big believer in that.

The products are always changing. You can't marry yourself to one vendor or another, or one type of technology. It's changing so fast. You have to constantly poll the universe, to see.

That's why companies like Gartner and Jupiter and all of these analytics companies are so important today. They help you through that very quickly. Who's acquiring what company? And how?

For instance the Adobe-K4 partnership was a big strategic partnership for Adobe. But there were other companies out there - like WoodWing and companies like that that were sort of doing the same work as K4. But you have to be aware that Adobe chose K4 to partner with. That sort of changes the editorial platform landscape. Five years from now, it might be something different.

You constantly have to be supplying that information to your business, and the business has to view technology as truly part of their core team. Information Technology is no longer the segregated group over in the corner administering e-mail and setting up the networks and all of that. It's really an integral spine of the businesses today.
Michael Moon:You'd mentioned one thing earlier, when we were talking about the catalytic events and/or business problems to solve. One was getting greater involvement with your community. This kind of leads into a larger conversation of social media, user-generated media and content.

Can you talk through this with us here how that lands within a publishing group such as yours? Abby DeMillo: Well, regarding user-generated content, it depends again on the business problem. If you're attempting to create a community of users, user-generated content might be a good way to go. If you have people on the outside who are contributing content to your site - enriching it in that way photo contests and contributed photography, but also contributed articles, too. And blogs, vlogs, podcasts, etc. All of these kinds of community things that are popping up are very, very important because they give your customers the power to contribute their thoughts and ideas and imagery to your site.

It's important in the content supply chain to be able to provide content to that, as well. RSS feeds are becoming a very big thing on websites today. Well, to do an RSS feed, you have to understand how that content is flowing at a dynamic level. I think that's, in a way, a part of a user community, as well. It's not necessarily usergenerated, but many users are incorporating RSS feeds in their daily life.

Whether or not you're having a photo contest on your website or if people are contributing words, giving people a voice has always been a very powerful thing. YouTube is a classic, classic example of user-generated community content and has become a powerful media tool in a very short amount of time.

Michael Moon: This is the last items we'll discuss, given our time. One of the more interesting things that I've seen in a social media, user-generated content space has been Wikipedia. More specifically, not the articles themselves, but the behind-the-scene discussions around what actually is valid or not valid, or a valid point of view or a biased point of view - et cetera, et cetera.

So the discussions - the socialization of the content that actually is formally published in the Wikipedia... The discussions tend to provide a much deeper, richer, more meaningful context for the actual published article. In fact, I might argue that in some cases, the discussions are more valuable than the article itself. 
Abby DeMillo: Wikipedia - I don't go on that too often, unless I'm looking something up. But I really do believe that the discussions behind the formal statements are really much more interesting to read. Because you get to see how the final statement has developed. The logic behind that and what people are really thinking about that particular subject. Wikipedia becomes its own community, in a sense, of people who really are concerned about how words and phrases are used in popular culture. Historical linguistics and understanding where language is coming from is a very passionate subject of learning and discussion with many people.

There's a huge community around that.

Michael Moon:Yes. This perhaps will allow us to summarize on perhaps a coda around this discussion. One could easily conclude that today we have too much information. The internet has only unleashed tsunami after tsunami of information overload.

Abby DeMillo: Yes. That's a true statement.

Michael Moon: What we have is a constrained ability to consume the existing information. Perhaps more importantly, the missing resource or the thing that every reader seeks to be able to engage the published information... We seek context. What does this mean? What does it mean to me? What action might this inform? What insight might this invoke in me?

So context tends to be the missing ingredient or the scarce resource in this post-internet age of ours.

Abby DeMillo:Yes. Really, you can't erase the "people" part of this. "People, process and technology." At the end of the day, the media itself is the message that affects the people. How do people get their news today? Do they sit every morning reading the newspaper or are they getting their sound bytes off of the internet or by listening to Fox News or CNN? In our office building we have monitors in the elevators feeding us news clips constantly. Does the news mean more if it is pushed to us or is it just easier to digest the sound bytes?

Michael Moon: I might even go further to say that it's the social interaction. The communication and the interaction and the collaboration. It's the social interaction that generates new context. Or deeper - more nuanced context.

Abby DeMillo: Or the demand for that.

Michael Moon:Yes.

So it's the socialization of the information. It's the communication, interaction and collaboration around the information. That's the juice, I believe.
Abby DeMillo: I do agree with that.

I think that community - companies like YouTube, for instance, have created an entire... I don't even want to say generation, because it spans generations, but an entire audience of viewers who want immediate media that is shared in a global way. It doesn't really matter if that message is tasteless or tacky or if it is poignant. The media itself spans the generations of people that are using media-visual feedback to do all sorts of things with very, very little investment. Look past what is being played and see how it is being played out - that is the future of communications.

Michael Moon: And when you look at one of the key demographic trendlines as it affects a company like McGraw Hill, the millennials the 20-year olds, today — are consuming less and less printed media. They're reading fewer magazines. They subscribe and read fewer newspapers. For the most part...

Abby DeMillo: They're living in sound bytes, that is probably true. So, it is our job to make those sound bytes meaningful. Whatever is digested has to make sense and has to have meaning to our lives.

Michael Moon: Not only they're living in sound bytes, but for a certain and very significant portion, the Daily Show with Jon Stewart is their primary source of news. Abby DeMillo: Yes. I know.

Michael Moon: When you think about that, what does that mean? What does the Daily Show really give you? It gives you context. That's the whole point of humor. Humor is the clash of context. Of action context.

Abby DeMillo: We really are changing. It's almost hard to even comment on it, because every day it's different. But should we put pressure on Jon Stewart to make his show meaningful? I think that what type of message (satire or sardonic humor for instance) needs to be understood by the audience. It is not up to us to say to the producers of The Daily Show, "You need to provide your audience with meaningful truth" because that is not what that show is about. But if Jon Stewart were to pass himself off as a serious journalist and his message as factual truth, then this would be a clash of context. Humor doesn't work against context, it just provides us with another viewpoint with which to comment on context. Michael Moon:Yes. 